\title{
Testicular Choriocarcinoma Revealed By Lower Digestive Bleeding: Case Report
}

Hicham Ncir", Zakaria Dahami, Mouhssine Errehan, Mohammed Oubihi, Mohammed Amine Lakmichi, Said Mohammed Moudouni, Ismail Sarf

Service d'urologie, CHU Mohammed VI, faculté de médecine et de pharmacie, université Cadi Ayyad, Marrakech, Maroc

DOI: $10.36347 /$ sjmcr.2020.v08i10.008

| Received: 28.09.2020 | Accepted: 05.10.2020 | Published: 15.10.2020

*Corresponding author: Hicham Ncir

\section{Abstract}

Choriocarcinoma are neoplasms that develop from testicular germ cells in humans. Testicular choriocarcinoma metastases are often hemorrhagic, mainly from the brain or lungs. Digestive metastasis is a rare and have a poor prognosis when they bleed. We report the observation of a young patient of 36 years, hospitalized for melena of average abundance, evolving in a context of general condition alteration, the radiological assessment discovers an intestinal intussusception with a peritoneal effusion of average abundance, hepatic and pulmonary nodules of probably metastatic origin. The urogenital examination finds an enlarged left testicle, the ultrasound confirms the presence of testicular nodules and the head of the epididymis of tumor-like appearance, the blood dosage of the hormone HCG is high, the patient underwent a median laparotomy with left inguinal orchiectomy, the anatomopathological and immunohistochemical study confirms the diagnosis of testicular choriocarcinoma. The frequency of atypical choriocarcinoma metastases is very low and treatment is mainly based on chemotherapy.

Keywords: Testicular Choriocarcinoma ; Lower Digestive Bleeding; intestinal invagination.

Copyright $(\mathcal{C} 2020$ The Author(s): This is an open-access article distributed under the terms of the Creative Commons Attribution 4.0 International License (CC BY-NC 4.0) which permits unrestricted use, distribution, and reproduction in any medium for non-commercial use provided the original author and source are credited.

\section{INTRODUCTION}

Choriocarcinoma is a testicular nonseminomatous germ cell tumor, it has a high metastatic potential by hematogenous diffusion, the most frequent metastatic sites are the lung $(80 \%)$, the occurrence of digestive metastasis indicative of testicular choriocarcinoma is exceptional. We report a rare case of gastrointestinal bleeding due to secondary localization of testicular choriocarcinoma.

\section{ObServation}

A 36-year-old patient, with no particular pathological history, consults for melena of average abundance, evolving for 20 days, in a context of weight loss estimated at $5 \mathrm{~kg}$. General examination found a patient with no fever, skin-mucous paleness. The urogenital examination revealed an enlarged left testicle, evolving for 6 months, but neglected by the patient (Fig. 1), and a finger cot soiled with melena during the digital rectal examination.

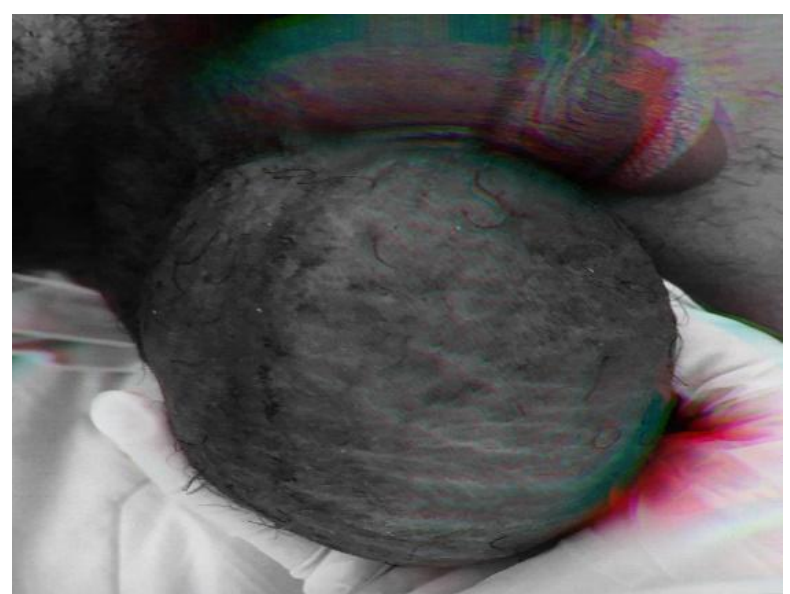

Fig-1: Local aspect of the scrotum

The thoraco-abdomino-pelvic computed tomography reveals an intestinal intussusception, with an average abundance of peritoneal effusion adding hepatic and pulmonary nodules of probably metastatic origin. (Fig. 2) 


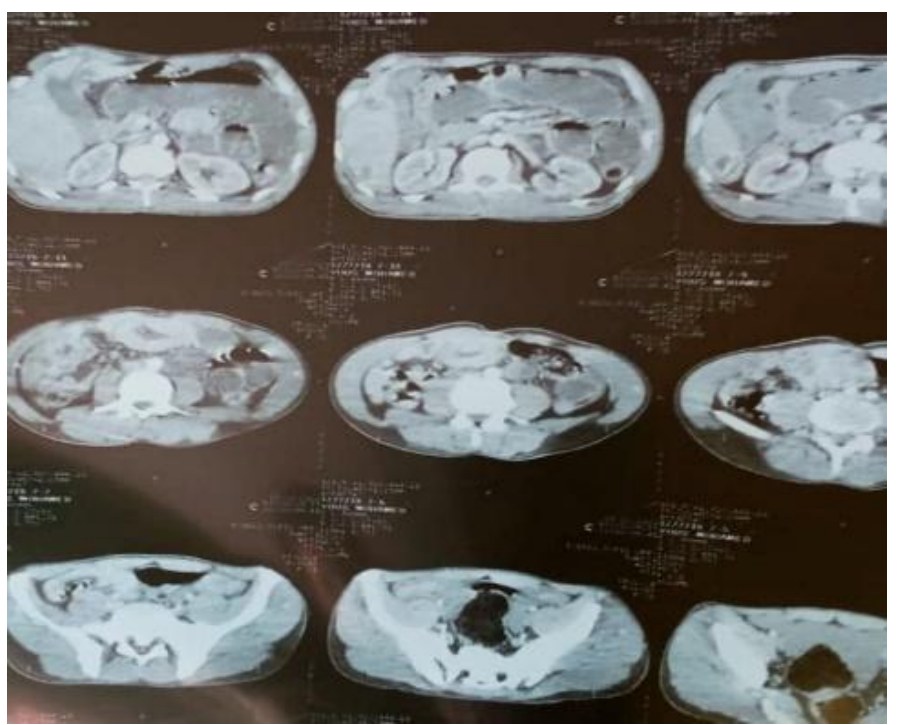

Fig-2: Scannographic aspect of intestinal invagination

The biological assessment found anemia at 2.7 $\mathrm{g} / \mathrm{dL}$, transfused by 7 red blood cells. The dosage of total HCGs is $866,999 \mathrm{IU} / \mathrm{L}$ for a normal of 0 to $3 \mathrm{IU} /$ L. The patient underwent an urgent laparotomy showing a hemoperitoneum associated with intussusception and the presence of 3 hepatic metastases mourning the blood. A grele-hail anastomosis resection with resection of a liver metastasis and an inguinal orchiectomy were performed. The anatomopathological study of the surgical specimen confirms the diagnosis of testicular choriocarcinoma, it should be noted that the urgent management of the patient did not allow us to conserve the sperm (Fig-3).

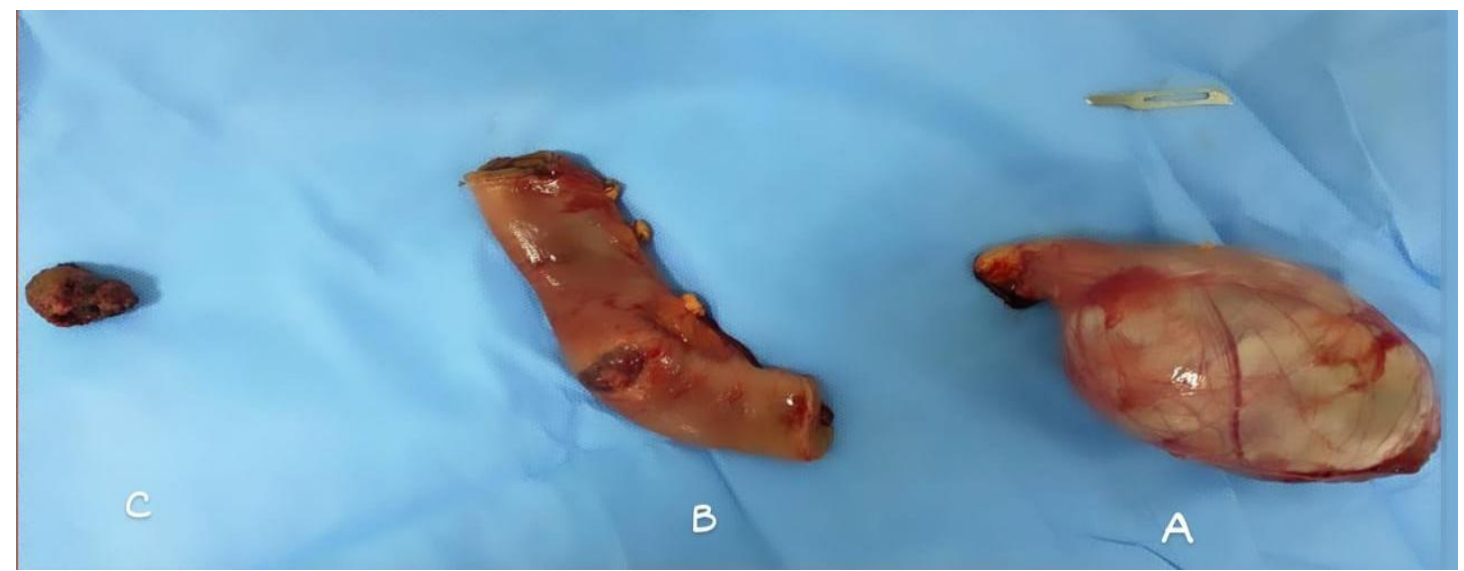

Fig-3: Postoperative image showing: A. the left testicle after orchiectomy, B. part of the intestine resected, C. hepatic metastasis resected

\section{DISCUSSION}

Testicular choriocarcinoma is a nonseminomatous germ cell tumor with a high metastatic potential by hematogenous diffusion. The most common sites of metastasis are the lung $(80 \%)$, brain (10\%), liver (10\%) and kidney (1.4\%) [1]. Few cases of gastrointestinal bleeding complicating metastases from testicular choriocarcinoma have been reported in the literature [2, 3]. Gastrointestinal bleeding can either be a way of revealing testicular tumor or a complication of an already known testicular neoplasm. The topographic diagnosis is difficult to establish. Endoscopy is especially useful for locating upper lesions [4]. Abdominal computed tomography with injection of contrast product seems promising.
Histologically, choriocarcinomas are composed of cytotrophoblast and syncytiotrophoblast cells, and show a positive reaction to cytokeratin and HCG on immunohistochemistry. Biologically, the dosage of HCG (total or beta fraction) is high and guides the diagnosis. While these diagnostic tests can be helpful, a laparotomy might be needed for diagnosis and early treatment in some cases. The therapeutic management of testicular choriocarcinoma is based on orchiectomy performed by inguinal route. Sperm storage must be systematically carried out beforehand unless the patient refuses [5]. The metastatic stages will benefit from three to four cycles of the BEP protocol: bleomycin, etoposide and cisplatin, the response to treatment is judged on the evolution data of -HCG, which decreases in the event of a response, before the 
radiological signs. The reassessment assessment is currently based on positron emission computed tomography data [6].

\section{CONCLUSION}

Gastrointestinal metastases from testicular choriocarcinoma are rare and have a poor prognosis, with a high hemorrhagic potential. Surgery should be decided without delay. Secondary digestive locations are when they bleed. Treatment is based on chemotherapy, which can improve the prognosis.

Declaration of Interests: The authors declare that they have no conflicts of interest in relation to this article.

\section{REFERENCES}

1. Houlgate A. Diagnostic et principe de traitement d'un cancer du testicule. Prog Urol. 2009; 19:2413.

2. Lock MR. Testicular tumour presenting as hematemesis. Postgrad Med J. 1975; 51:857-9.

3. Motzer RJ, Bosl GJ. Testicular choriocarcinoma. Urology. 1987; 30:119-22.

4. Hsu CC, Chen JJ, Changchien CS. Endoscopis features of metastatic tumors in the upper gastrointestinal tract. Endoscopy. 1996; 2:249-53.

5. Camparo P, Durand X, Avances C, Culine S, Segui B, Rigaud J, des Lésions Urologiques GD. Particularités histologiques et principes de traitements des tumeurs du testicule du sujet âgé. Progrès en urologie. 2009 Nov 1;19:S142-6.

6. El Fekih LE, Hassene H, Fenniche S, Ben AH, Belhabib D, Megdiche ML. Pulmonary metastases revealing choriocarcinoma. La Tunisie medicale. 2010 Jan;88(1):49. 